Appl. Set-Valued Anal. Optim. 1 (2019), No. 3, pp. 203-204

Available online at http://asvao.biemdas.com

https://doi.org/10.23952/asvao.1.2019.3.01

\title{
EDITORIAL A SPECIAL ISSUE DEDICATED TO ALFRED GÖPFERT
}

It is a great pleasure for the guest editors to dedicate a special issue to their supervisor, teacher, friend and colleague, Prof. Dr. habil. Alfred Göpfert. On the occasion of his 85th birthday, we would like to acknowledge his outstanding work as a scientist and as a human being whose original and deep ideas have had great influence not only on the development of various fields in mathematics but also on the development of a generation of mathematicians.

Professor Alfred Göpfert started his scientific career in the early 1960 as a PhD student in the research group of Professor Herbert Beckert at the University of Leipzig. In this period he was dealing with approximation methods concerning boundary and initial value problems in partial differential equations. At the same time, he also found a deep interest in convex analysis and optimization theory. In 1974, Professor Göpfert became full professor of mathematics at the Technical University of Leuna-Merseburg. He established there his well-known research group, which later gained interesting results in the theory of optimization in general spaces.

Professor Alfred Göpfert profound professional skills, together with his charisma and his ability to motivate his co-workers, were the very foundation of his success. For many years, students of mathematics and PhD students in Leipzig, Merseburg and Halle benefited from his carefully given lectures. His presentations always impressed the audience with their clarity and precision. It is important to mention that his understanding of being a scientist necessarily involved taking over political and organizational responsibilities. He has been and continues to be active in quite a number of national and international committees and on the editorial boards of scientific journals such as Optimization. In addition, he was Dean, Vice-Rector and Rector of the Technical University of Merseburg, before he was offered the chair of Convex Analysis and Optimization at the Martin-Luther-University Halle-Wittenberg. It was and is always a great pleasure for all members of the research group Optimization to have a fruitful discussion with Professor Alfred Göpfert during the research seminars - that he is visiting till today.

His numerous publications in scientific journals, and his monographs have contributed to the further development of optimization theory. His book Mathematische Optimierung in Allgemeinen Vektorräumen, which appeared in 1973, was one of the first in its field and set standards for the development of a subsequent research. Furthermore, his textbooks Funktionalanalysis, 
Angewandte Funktionalanalysis, Approximation und Nichtlineare Optimierung in Praxisaufgaben and his monographs Vektoroptimierung: Theorie, Verfahren und Anwendungen and Variational Methods in Partially Ordered Spaces are important contributions on the fields of convex analysis and optimization theory, and each of these books will be used now as before by students and researchers.

The objective of this special issue is to present advances in different areas of applied analysis and optimization theory, recent results in variational analysis and corresponding applications.

The aim of the paper by Christian Günther, Elisabeth Köbis and Nicolae Popovici is to develop two algorithms for computing all strictly minimal elements of a nonempty finite family of sets in a real linear space, with respect to a preorder relation defined on the power set of that space.

Stefan Hamann shows sufficient conditions for strictly efficient points as well as for superefficient points in vector optimization. Especially, a sufficient condition for Henig properly efficient points is given.

In the survey paper by Niklas Hebestreit, a detailed introduction to some of the recent developments in the field of vector variational inequalities and related problems is given including a brief analysis of stochastic vector variational inequalities, generalized problems and numerical methods.

Akhtar Khan, Niklas Hebestreit and Christiane Tammer study inverse problems for vector variational and vector quasi-variational inequalities and gave existence results for the regularized output least-square-based optimization problem. An application to the famous Markowitz portfolio problem is presented.

In the paper by Truong Q. Bao, Thanh Tam Le, Christiane Tammer and Vu Anh Tuan, duality assertions for vector optimization problems with respect to variable domination structures are derived by using new nonlinear scalarizing functionals.

Caiping Yang and Songnian He study a new general iterative method for finding a fixed point of a Lipschitz continuous pseudo-contractive mapping defined on a closed convex subset of a real Hilbert space. The main advantage of the method is that its convergence does not require the compactness assumption on the operator under consideration. This superiority is also demonstrated by comparing the numerical performances of the method and the Ishikawa iteration process in solving an example.

The guest editors would like to express their thanks to the authors for their contributions and to the referees for their valuable comments.

Rosalind Elster

Halle (Saale), Germany

E-mail address: r.elster@t-online.de

Christiane Tammer

Martin Luther University of Halle-Wittenberg, Germany E-mail address: christiane.tammer@mathematik.uni-halle.de 